\title{
Critical Care in Africa: A Surgical Intensivist Perspective
}

\section{J.B.A. Macleod}

Rahima Dawood Travelling Fellow 2010

Correpondence to: Jana Macleod (Bacote), Email: janamac@outlook.com

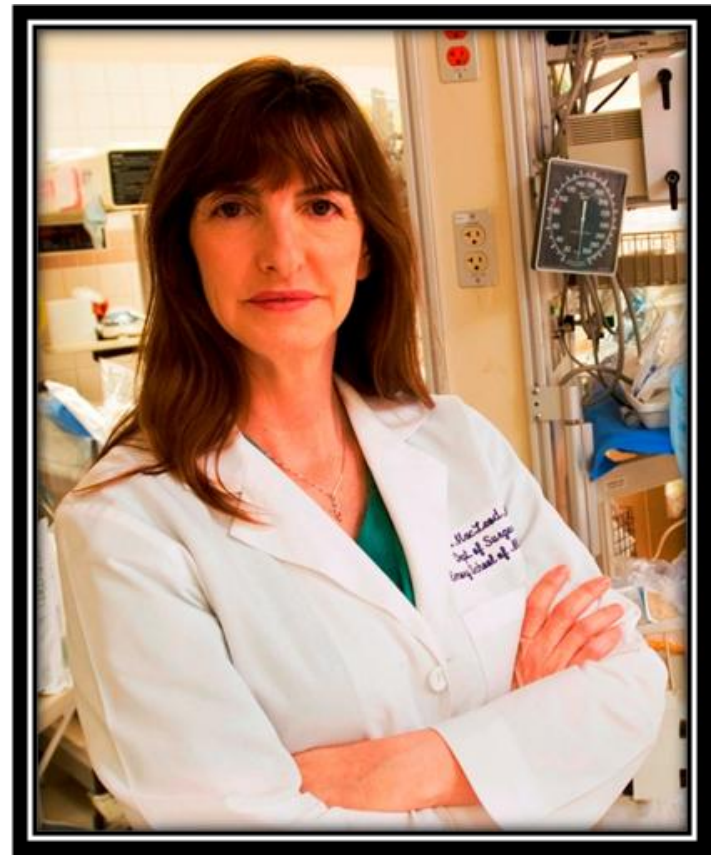

Jana B.A. Macleod, MD MSc, FRCS(C), FACS, FRC(ECSA)

Rahima Dawood Travelling Fellow 2010

Critical care services often fall far outside the focus of mainstream health care agendas. The disease specific list held by many health care stakeholders, including the funding agencies, results in a funneling of political attention and funds predominantly in those directions. Infectious diseases, in particular tuberculosis and HIV/AIDS, are on the fore front of the global public health agendas and rightfully, will remain high on the list for the foreseeable future ${ }^{1}$. Childhood infectious diseases also represent disease-specific agendas that are a main target of donor funding because of the potential for intervening successfully and the potential of life saved ${ }^{2,3}$. The lure of eradication of a disease with a heavy burden on the health of the population as exampled by the Polio campaigns and programs to eradicate guinea worm easily capture the attention of governments and society alike. As a result, crucial life-saving hospital services such as critical care are often overlooked.

Critical care, or intensive care, as it is commonly referred to, is the health care service that provides care for patients with acute life-threatening illnesses and injuries, in other words, the sickest patients in the hospital. It is an in-hospital service by virtue of its function therefore, with the growing attention on prevention and promotion of health, the hospital and its services are often abandoned. Trauma is a common cause for admission to a critical care unit and it is an excellent example of a disease burden with an increasing focus on prevention yet still associated with a high mortality rate ${ }^{4}$. In the 
resource limited setting, the injury-related mortality rate is often unaddressed despite carrying the highest frequency among the global trauma death rates ${ }^{5}$.

Though, the tri-modal temporal distribution of injury deaths does reflect a need for primary prevention measures, many authors have recognized that a significant portion of trauma deaths will not be saved by these types of interventions alone. ${ }^{6}$ of those trauma patients who arrive alive at the hospital, a significant number continue to die despite present hospital care. Therefore, significant portions of injury-related death occur in the hospital, and often in the critical care unit. In the country of Columbia, Masella and his colleagues showed that trauma patients who died after 72 hours in hospital contributed a larger proportion of all trauma deaths occurring as compared to the proportion of deaths occurring in this time period after injury in the North American hospital setting. In this study, the authors noted that trauma deaths in North American hospitals were more often occurring in the classic golden hour, or early postinjury period with a much smaller number during the stay in the critical care unit. ${ }^{7}$ The authors suggest that under-developed critical care accounts for a large portion of this difference in trauma deaths between the two regions of the world. Other than highly successful primary prevention programs such as the vaccination campaign which eradicated small pox in 1979, the response to injuries and illness will continue to require the attention of health care facilities and not just primary prevention alone. ${ }^{8}$

The global burden of critical care illness is substantial. In the US, the growth of critical care units and the patients to fill them continues to grow as the population ages and the prevalence of co-morbidities such as obesity and diabetes rise. ${ }^{9}$ It has been shown that since 1991 conditions that often require critical care like multiple organ failure, sepsis and acute renal failure have been on the increase. ${ }^{10}$ The Society of Critical Care Medicine, a professional organization based in the US, estimates that as of 2004 there are 6,000 intensive care units across the US that care for over 66,000 patients annually which amounts to approximately 55,000 patients daily being treated in an intensive care unit in the USA. ${ }^{10,11}$ Despite the growth of these services, the demand is growing even faster and it is forecast that the health care personnel needs to meet the critical care demand of future patients in 2020 will fall short by at least 35\%.12,13

In Africa, the need for critical care is even greater. It is reasonable to assume that a patient who dies would likely have warranted appropriate critical care services if they had been admitted to or attempted to go to a facility that offered such services. Therefore, death can be taken as a proxy measure for the amount of high acuity illness and therefore the need for critical care services. Epidemiologically speaking, the vast majority of global deaths occurring annually, mainly from treatable etiologies, happens in low and middle-income countries. ${ }^{14}$ of the 10 million children under the age of 5 years who die annually, $90 \%$ die in the 42 poorest countries of the world. ${ }^{2}$ It is estimated that $90 \%$ of the trauma-related mortality in the world also occurs in low and middle-income countries. ${ }^{15}$ Finally, $50 \%$ of all maternal deaths that ensue during pregnancy and childbirth occur in developing countries. ${ }^{16}$ Critical care services in the developing world are urgently needed to address the weight of these serious conditions and their associated mortality.

Critical care units in Africa do exist and were started as early as the 1960s with published case reports and cohort studies of critically ill patients cared for in intensive 


\section{5

care settings appearing in the medical literature as early as the $1970 \mathrm{~s} .{ }^{17}$ In Nigeria in 1986, a review of 100 critically ill patients cared for in an intensive care unit in Lagos reported a mortality rate of $38 \%$ with a high incidence of sepsis. ${ }^{18}$ But now 5 decades later, the number of available critical care services across Africa is still sporadic. ${ }^{19}$ In the US it is estimated that $13.4 \%$ of all the hospital beds are dedicated to intensive care with this number expected to rise relatively as the number of in-patient beds reduces. ${ }^{20}$ In contrast, Cape Town South Africa is estimated to have allocated only $6.6 \%$ of all beds to critical care and other countries in the region such as Zambia report a similarly low proportion. ${ }^{21}$ In a survey of anesthetic services in 68 hospitals in Zambia, only $7 \%$ of the hospitals responded positively to having a critical care unit. ${ }^{22}$ Compounding the paucity of services is the urban-rural distribution skew. The majority of units are found in tertiary care centers and major urban locations of the African countries when they do exist. Therefore, critical care services are usually available only to those with the resources for transport or who have access to privately funded care.

Consequently, as a result of this paucity of services, even those patients who seek hospital care often do not receive the intensity of care they require to survive their illness. Molyeux and colleagues performed a cohort study of pediatric emergencies presenting to various pediatric emergency departments across the developing world and showed that $50 \%$ of the children died within 24 hours after admission, reflecting a paucity of acute and critical care resources. ${ }^{23}$ In a community, non-tertiary hospital in a north-eastern state of South Africa, a review of admitted hospital patients showed that $25 \%$ met criteria that would warrant being admitted to a critical care unit had they been admitted to a hospital with such a unit. ${ }^{21}$ The acuity of illness of a large proportion of the patients that present in the accident and casualty departments, operating rooms and wards of low income countries is high. Many factors from predisposing patient factors of malnutrition, anemia and high prevalence of HIV to the many cultural and socioeconomic reasons that result in patients presenting late all contribute to this high acuity at presentation to a health care facility. Thus in low and middle-income countries the challenge for critical care is significant with a potentially larger burden on hospitals in developing countries than is presently seen in other parts of the world. ${ }^{15}$

The concepts that underpin critical care started as early as the $19^{\text {th }}$ century, when the first nurse Florence Nightingale recognized that post-operative patients did much better if they were cared for together in the same location in the hospital. ${ }^{24}$ In World War II, clumping the newly injured soldiers together in resuscitation rooms was shown to utilize resources more effectively and improve outcomes. ${ }^{25}$ After the iron lung saved thousands of lives during the polio campaign of the late 40s and Forrest Bird invented the mass-producible Bird respirator in 1949, the modern critical care unit as a location to nurse and care for severely ill and injured patients became an important service provided by major hospitals. However, increasingly complex and expensive advances in the provision of critical care to patients has lead hospital workers, funders and governments to lose the understanding of these original and underlying tenets of critical care. These concepts which are the foundation of the early critical care services still hold value and should continue to be a key tenant in modern critical care.

Surgical intensivists in many parts of the world have revived this important concept and it is best reflected by recent comments that reflect the modern intensivist's approach "Intensive care is not simply a location for care but an approach to care". As essential as 
this understanding is to the care of the critically ill in the developed world, it also needs to be completely adopted in the developing world as new services of critical care are fashioned. The main point behind this concept is to understand that the location is secondary to the care that is given and in a resource constraint world that paradigm is paramount to put forward. The expansion of and introduction to critical care in the developing world is often thwarted by the perceptions that critical care is hugely expensive, extremely complex and requires extensive additional training. While many critical care units operating in the developed world would fit that description completely, there lacks robust scientific evidence that outcome is changed by many of these technologies and approaches.

Equipment that is highly technological and thereby expensive is believed to be an essential component of critical care for sick patients. In fact, many of these expensive pieces of equipment seen in US intensive care units are often sparsely used and lack scientific merit as to their role in improving outcomes. ${ }^{26}$ Medical technologies, such as continuous veno-venous dialysis, the use of the ECMO machine to maintain oxygenation in adults and high pressure jet mechanical ventilation in difficult to oxygenate patients are just a few examples of treatments that lack Level I scientific evidence of mortality reduction in critically ill populations, despite case report level literature of their potential clinical utility. Other medical technologies, for example, the right heart pressure catheters known as Swan-Ganzwere once extensively used but were recently the focus of randomized control trials that show no value in their use in surgical patients ${ }^{27}$. Expensive equipment should not be a reason to block the start-up or improvement of critical care in a resource constraint hospital. Timely, coordinated care that provides early institution of treatments such as fluid resuscitation and antibiotics has been shown to reduce mortality where technology often has not. ${ }^{28,29}$

However, there is a cost to increasing the intensity of care to sick patients even without extensively increasing the technology used. Staff to patient ratios, the consistent availability of supplies and increased training of personnel all adds to the hospital budget.Unfortunately, there have not yet been published studies of the costeffectiveness of critical care interventions in low and middle income countries to enlighten these issues. But, Gosselin and colleagues have recently published 2 articles on the cost-effectiveness of resource intensive surgical services which are reflective of the majority of patients who land in intensive care units. He was able to show in Sierra Leone that the cost of emergency surgical services was only $\$ 13.72$ per averted DALY (disability adjusted life year) and though in Nigeria the cost of trauma services was more expensive at $\$ 172.00$ per averted DALY, both are well within the cost of other global public health programs. ${ }^{30,31}$

Critical care has a cost but its value can be appreciated when its implementation and associated improved outcome can show overall effectiveness and thereby benefit to society. Unlike, developed countries, a larger proportion of critically ill patients are young. With the proportion of cases that result from either trauma or emergency obstetric cases alone, the average age of the critically ill and injured patient who potentially could be saved is much lower in developing countries than other parts of the world $^{22}$. This can potentially lead to a much larger overall benefit to society. Further, many of these younger patients are otherwise healthy with fewer co-morbidities such as diabetes, obesity and vascular disease, than is found in patients in developing 
countries. Therefore, not only is it likely that critical care services in low income countries can increase survival, their potential to increase the survival of the economically productive segment of a population within a society could be enormous. ${ }^{15,26,32}$

The complexities of the services provided are also often cited as an obstacle to the provision of care in developing countries. In North America and Europe, both nurses and doctors undergo further additional training in order to work and care for critically ill patients which is usually full-time courses that require formal evaluation for completion and obtaining of either a degree or certification. In developing countries, similar courses for personnel exist, mainly for critical care nursing but are sparse in their numbers in relation to need. ${ }^{33}$ In East Africa, there are no specialized formal training programs for doctors in critical care. However, the implementation of short courses for critical care has been shown to be useful. Increasing the recognition of critical ill patients, as well as the ability to respond appropriately was taught effectively in a 4 day critical care course (FCCS) given to nurses and medical officers in Kenya. ${ }^{34}$ Surgical residents and medical officers who work in rural locations improved both their knowledge and their ability to perform critical procedures in a 4 day critical care course taught in Kenya and Zambia. ${ }^{35}$ Therefore, the knowledge and skills necessary to support critically ill patients can be provided to a wide cadre of health care personnel using shorter courses that can act as a complement to the development of future formal courses and fellowships.

With the small number of formally trained intensivists and critical care nurses in developing countries and the utilization of short courses to increase the appropriate approach to critical care for the sick, care can be simplified by the use of protocols or guidelines. There has been a wide spread adoption of the surgery checklist after it was shown to reduce mortality by $30 \%$ across many regions of the world. ${ }^{36} \mathrm{~A}$ similar approach to many aspects of critical care can also be adopted. The surviving sepsis campaign has outlined a group of interventions, referred to as the sepsis bundle that may increase survival after sepsis. Though there remains controversy over the exact composition of the sepsis bundle, Levy and colleagues were able to show a correlation between sepsis bundle compliance and reduction in mortality as compared to hospital programs where compliance was poor. ${ }^{37}$ Further, there are bundles like the ventilatorassociated pneumonia prevention bundle which is well substantiated in the literature as effective and many of the components are low cost maneuvers such as elevation of the head of the bed to greater than $30^{\circ} .{ }^{38}$ Therefore, these and other care bundles can assist in minimizing complexity of care that may be an obstacle to wide spread implementation.

As critical care expands in Africa, what is the role of the specialty of surgery in that expansion? From its beginnings, surgery has played a pivotal role in critical care. The first intensive care unit in the US is credited to a surgeon, Dr Dandy at Johns Hopkins University Hospital in Baltimore. Dr Dandy who worked with the world famous neurosurgeon Dr Drake, opened a 3 bed intensive care unit to care for his postoperative neurosurgical patients in 1927.24 Even today, the second most common reason for admission to an intensive care unit in the US is post-operative care. ${ }^{10}$ Even in the developing world, surgical disease is a common underlying process in the critically ill. In Nigeria, a recent review of admissions showed that $66.7 \%$ or two-thirds of the 


\section{8

critical care admissions were surgical admissions ${ }^{39} \mathrm{~A}$ study from a rural mission hospital in Kenya showed that $50 \%$ of their ICU admissions were for post-operative care. ${ }^{40}$ Therefore, professional bodies such as the College of Surgeons of East, Central and Southern Africa (COSECSA) and others need to recognize the importance of surgical critical care as an invaluable service and support its growth directly through services delivered by surgeons as well as other health care professionals.

Critical care is a specialty that is usually acquired after the first specialty of medicine, pediatrics, anesthesia or surgery is completed. Even more recently, the specialty of emergency medicine can now be complemented by adding critical care fellowship training after completion in the US. Though the background training of the medical staff may vary depending on the location of the critical care unit, effective care that reduces mortality has been shown to result from the utilization of an intensivist model. ${ }^{41}$ The intensivist model of service delivery rests on having a doctor fully available in the intensive care unit to direct rounds and respond to changes in patient's condition while utilizing the support of a multi-disciplinary care team. This approach has been shown to reduce mortality in many intensive care settings in developed countries. In particular, the availability and timeliness of response by the intensivist to changes in the patient's condition appear to be the most crucial component of this model of service delivery. ${ }^{42}$ Surgical training needs to include a significant amount of critical care in its curriculum and becoming a surgical intensivist should be a sub-specialty that is promoted and encouraged for young African surgeons.

Critical illness and injury is a health care burden disproportionately carried in developing countries. It, however, can be addressed by low cost and effective interventions that avoid the pitfalls of high technology and extensive expertise as is often used in developed country models. Surgery can play a key role in the expansion of critical care in Africa as a large portion of the patients have surgical disease. Therefore, COSECSA, other professional bodies, medical schools and health care training grounds should encourage young surgeons to consider critical care as a viable and valuable subspecialty that can significantly impact the survival of surgical patients in their hospital, country and region.

\section{References}

1. The Injury Chart Book: A graphical overview of the global burden of injuries. Department of Injuries and Violence Prevention Noncommunicable Diseases and Mental Health Cluster. World Health Organization, Geneva 2002.

2. Black RE, Morris SS \& Bryce J. Where and why are 10 million children dying every year? Lancet. 2003 Jun 28. 361(9376):2226-34.

3. Mccarthy JE \& Evans-Gilbert T. Descriptive epidemiology of mortality and morbidity of health-indicator diseases in hospitalized children from western Jamaica. American Journal of Tropical Medicine \& Hygiene. 2009 April. 80(4):596-600.

4. Sauaia A, Moore FA, Moore EE, et al. Epidemiology of trauma deaths: a reassessment. J Trauma 1995. Vol 38: 185-93.

5. Krug EG, Sharma GK, Lozano R. The global burden of injuries. Am J Public Health 2000; 90:523-526.

6. Hoyt DB, Coimbra R, Potenza B, Doucet J, Fortage D, Holingsworth-Fridlund P \& Holbrook T. A Twelveyear analysis of disease and provider complications on an organized level I trauma service: As good as it gets? Journal of Trauma 2003. Vol 54:26-37. 
7. Masella CA, Pinho VF, Cosat P, Afonso D, Spencer N, Fernando AC, Rizoli, S \&Scarpelini S. Temporal distribution of trauma deaths: quality of trauma care in a developing country. J Trauma - Injury Infection \& Critical Care. Sept 2008. 65(3):653-8.

8. "Smallpox". WHO Factsheet. Http://www.who.int/mediacentre/factsheets/smallpox/en/

9. Last date retrieved December 2011.

10. Society of Critical Care Medicine. Critical Care Units: A Descriptive Analysis, 1st Edition. Des Plaines, Illinois: Society of Critical Care Medicine, 2005.

11. Critical Care Statistics in the United States. Society of Critical Care Medicine 2006. Http://www.sccm.org/aboutsccm/Public\%20Relations/Pages/Statistics.aspx.

12. Last date retrieved December 2011.

13. Halpern NA \&Pastores SM. Critical care medicine in the United States 2000-2005: an analysis of bed numbers, occupancy rates, payer mix, and costs. Crit Care Med. 2010. Vol 38:65-71.

14. Pronovost PJ, Needham DM, Waters H, et.al. Intensive care unit physician staffing: financial modeling of the Leapfrog standard. Crit Care Med. 2004. Vol 32:1247-1253.

15. U.S. Department of Health and Human Services Health Resources and Services Administration. Report to Congress: The Critical Care Workforce: A Study of the Supply and Demand for Critical Care Physicians. May 2006.

16. WHO Fact Sheets. Http://www.who.int/mediacentre/factsheets/fs310/en/index2.html

17. Last date retrieved December 2011.

18. Mock C, Kobusingye O, Joshipura M, Nguyen S \& Arreola-Risa C. Strengthening trauma and critical care globally. Current Opinion in Critical Care 2005. Vol 11: 568-575.

19. Pearson L \& Shoo R. Availability and use of emergency obstetric services, Kenya Rwanda Southern Sudan and Uganda. International Journal of Gynaecology and Obstetrics 2005. Vol 88: 208-215.

20. Sodipo JO. Experience with an intensive care unit in a developing country. Critical Care Medicine. 3(4):166-9. 1975 Jul-Aug.

21. Oji A. Intensive care in a developing country: a review of the first 100 cases. Annals of the Royal College of Surgeons fo England. 68(3):122-4. 1986 May.

22. Lipman J \&Lipman AR. Critical care in Africa. North to south and the future with special reference to southern Africa. Critical Care Clinics April 1997. 13(2): 255-65.

23. Halpern NA, Pastores SM \& Greenstein RJ. Critical care medicine in the United States 1985-2000, an analysis of bed numbers use and costs. Critical Care Medicine 2004. Vol 32: 1254- 1259.

24. Van Zyl-Smit R, Burch V \&Willcox P. The need for appropriate critical care service provision at nontertiary hospitals in South Africa. South African Medical Journal 2007. Vol 97: 268-270.

25. Jochberger $S$, Ismailova $F$, Lederer $W$ et al. Anesthesia and its allied disciplines in the developing world, a nationwide survey of the Republic of Zambia. Anesthesia and Analgesia 2008. Vol 106: 942-948.

26. Molyneux E. Paediatric emergency care in developing countries. Lancet 2001. Vol 357: 86-87.

27. Weil MH. Tang W. From intensive care to critical care medicine: a historical perspective. American Journal of Respiratory \& Critical Care Medicine June 2011. 183(11):1451-3.

28. Murray MJ. Review: the influence of armed conflict on the development of critical care medicine. Military Medicine June 201. 176(6):674-8.

29. Adhikari N, Fowler KJ, Bhagwanjee RA, Satish R \& Gordon D. Critical care and the global burden of critical illness in adults. Lancet. 2010 Oct 16. Vol 376(9749): 1339-46.

30. Sandham JD, Hull RD, Brant RF, Knox L, Pineo GF, Doig CJ, Laporta DP, Viner S, Passerini L, Devitt H, Kirby A, \&Jacka M. A randomized, controlled trial of the use of pulmonary-artery catheters in high-risk surgical patients. Canadian Critical Care Clinical Trials Group. NEJM Jan 2, 2003. Vol (1):5-14.

31. Dellinger RP, Carlet JM, Masur H, Gerlach H, Calandra T, Cohen J, Gea-Banacloche J, Keh D, Marshall JC, Parker MM, Ramsay G, Zimmerman JL, Vincent JL, \& Levy MM. Surviving Sepsis Campaign Management Guidelines Committee. Critical Care Medicine March 2004. 32(3):858-73.

32. Rivers E, Nguyen B, Havstad S, Ressler J, Muzzin A, Knoblich B, Peterson E, \&Tomlanovich M. Early GoalDirected Therapy Collaborative Group. Early goal-directed therapy in the treatment of severe sepsis and septic shock. NEJM. Nov 8 2001. Vol 345(19):1368-77.

33. Gosselin RA, Maldonado A, \& Elder G. Comparative cost-effectiveness analysis of two MSF surgical trauma centers. World Journal of Surgery March 2010. Vol 34(3):415-9.

34. Gosselin RA, Thind A, \&Bellardinelli A. Cost/DALY averted in a small hospital in Sierra Leone: what is the relative contribution of different services?. World Journal of Surgery April 2006. Vol 30(4):505-11.

35. Baker T. Critical care in low-income countries. Tropical Medicine \& International Health February 2009. Vol 14(2):143-8. 
36. Dunser MW, Baelani I, \&Ganbold L. A review and analysis of intensive care medicine in the least developed countries. Critical Care Medicine April 2006. Vol 34(4):1234-42.

37. Macleod JB, Jones T, Aphivantrakul P, Chupp M \& Poenaru D. Evaluation of fundamental critical care course in Kenya: knowledge, attitude and practice. Journal of Surgical Research May 15th 2011 . Vol 167(2): 223-230.

38. Macleod JB, Okech M, Labib M, Aphivantrakul P, Lupasha E, \&Nthele M. Evaluation of Trauma and Critical Care Training Courses on the Knowledge and Confidence of Participants in Kenya \& Zambia. World Journal of Surgery January 2011. Vol 35(10): 9-16.

39. Haynes AB, Weiser TG, Berry WR, Lipsitz SR, Breizat AH, Dellinger EP, Herbosa T, Joseph S, Kibatala PL, Lapitan MC, Merry AF, Moorthy K, Reznick RK, Taylor B, \&Gawande AA. Safe Surgery Saves Lives Study Group. A surgical safety checklist to reduce morbidity and mortality in a global population. NEJM Jan 29 2009. Vol 360(5):491-9.

40. Levy MM, Dellinger RP, Townsend SR, Linde-Zwirble WT, Marshall JC, Bion J, Schorr C, Artigas A, Ramsay G, Beale R, Parker MM, Gerlach H, Reinhart K, Silva E, Harvey M, Regan S, \& Angus DC. The Surviving Sepsis Campaign: results of an international guideline-based performance improvement program targeting severe sepsis. Intensive Care Medicine February 2010. 36(2):222-31.

41. Lorente L, Blot S, \&Rello J. New issues and controversies in the prevention of ventilator-associated pneumonia. American Journal of Respiratory \& Critical Care Medicine Oct 1 2010. Vol 182(7):870-6.

42. Abubakar AS, Ojo E, El-Nafaty A, \&Edomwonyi N. An Audit Of One-Year Intensive Care Practice In A Developing Country. The Internet Journal of Anesthesiology 2008.Vol 18 Number 2.

43. Riviello E, Kijabe Hospital, Kenya. Unpublished communication to author.

44. Nathens AB. Maier RV. Jurkovich GJ. Monary D. Rivara FP. Mackenzie EJ. The delivery of critical care services in US trauma centers: is the standard being met? Journal of Trauma-Injury Infection \& Critical Care April 2006. Vol 60(4):773-83.

45. Russell D, vorderbruegge M, \& Burns SM. Effect of an outcomes-managed approach to care of neuroscience patients by acute care nurse practitioners. American Journal of Critical Care July 2002. Vol 11(4):353-62. 